\title{
Incomum caso de eritema multiforme
}

\author{
Unusual case of erythema multiforme
}

\author{
Graciele Rui \\ Mauricio Marcon* \\ João Paulo De Carli** \\ Maria Salete Sandini Linden ${ }^{* * *}$ \\ Soluete Oliveira da Silva ${ }^{* * *}$
}

\section{Resumo}

Introdução: o eritema multiforme (EM) constitui uma enfermidade que pode envolver pele e mucosas, sendo de grande importância clínica pela frequência e variedade de entidades que pode representar. Apresenta difícil diagnóstico, podendo estar relacionada a um estado de hipersensibilidade do paciente. Objetivo: este trabaIho objetiva relatar um caso incomum de EM relacionado ao uso de antidepressivo. Relato de caso: paciente feminino, 38 anos de idade, relatando aparecimento de úlceras precedidas por bolhas na cavidade bucal há, aproximadamente, um mês após iniciar um tratamento antidepressivo utilizando cloridrato de bupropiona. Avaliou-se a história e os aspectos clínicos das lesões cutâneas e bucais, bem como os achados histopatológicos e de imunofluorescência, excluindo-se, assim, os diagnósticos diferenciais e chegando-se ao diagnóstico de EM. O tratamento da paciente se deu por meio do uso de corticosteroides orais tópicos e sistêmicos, e pela supressão da droga antidepressiva. Considerações finais: por se tratar de uma enfermidade que pode acometer a cavidade bucal, resultando em lesões ulceradas extensas e muito desconfortáveis ao paciente, seus aspectos clínicos, de diagnóstico, tratamento e prognóstico devem ser conhecidos pelo cirurgião-dentista.

Palavras-chave: Antidepressivo. Diagnóstico. Eritema multiforme. Terapia.

\section{Introdução}

As lesões vesiculobolhosas constituem um grupo variado de doenças que ocorrem na cavidade bucal, de grande importância clínica pela forma variada com que se apresentam, pela frequência observada e também pela dificuldade de diagnóstico de algumas dessas desordens. Por serem alterações autoimunes ou de hipersensibilidade, a aparência clínica é muito semelhante, porém a etiologia, muitas vezes, é difícil de ser encontrada, necessitando, assim, de um estudo minucioso dessas lesões. O objetivo deste trabalho foi realizar uma revisão de literatura e apresentar um caso clínico de uma lesão desse grupo.

O eritema multiforme (EM) é uma reação inflamatória aguda, imunitária, rara, de hipersensibilidade, que acomete indivíduos sem apresentar índice de prevalência. Apresenta manifestações clínicas que atingem pele e mucosa, podendo ser leves, moderadas ou graves ${ }^{1,2}$. A causa, muitas vezes, é de difícil descoberta, está relacionada à hipersensibilidade do paciente, podendo ser desencadeada por fármacos, alimentos ou infecções ${ }^{3}$. O tratamento é paliativo, pois a doença se manifestará toda vez que o paciente tiver contato com a substância causadora. O penfigoide benigno das membranas mucosas (PBM) é, na maior parte das vezes, o diagnóstico

\footnotetext{
Cirurgiões-dentistas graduados pela Faculdade de Odontologia da Universidade de Passo Fundo, Passo Fundo, Rio Grande do Sul, Brasil.

Doutor em Estomatologia pela Pontifícia Universidade Católica do Paraná, Curitiba, PR. Professor da Faculdade de Odontologia da Universidade de Passo Fundo, Passo Fundo, Rio Grande do Sul, Brasil.

*** Doutora em Implantodontia pela Universidade São Leopoldo Mandic, Campinas, SP. Professora da Faculdade de Odontologia da Universidade de Passo Fundo, Passo Fundo, Rio Grande do Sul, Brasil.

**** Doutora em Estomatologia pela Pontifícia Universidade Católica, Porto Alegre, RS. Professora da Faculdade de Odontologia da Universidade de Passo Fundo, Passo Fundo, Rio Grande do Sul, Brasil.
} 
diferencial do EM, assim como o pênfigo vulgar (PV), que das lesões vesiculobolhosas autoimunes é a mais agressiva ${ }^{2,3}$.

\section{Revisão da literatura}

O EM é uma doença que pertence às desordens inflamatórias agudas, caracterizada por acometer a pele e/ou a mucosa com o aparecimento de máculas vermelhas (eritema) que evoluem para vesículas, bolhas e úlceras (multiforme). As lesões quase sempre se distribuem simetricamente, apresentando tamanho variável e aspecto de anéis concêntricos ${ }^{1}$. Os pacientes, geralmente, apresentam sintomas sistêmicos como febre, dores articulares e mal-estar em geral, como se fossem sintomas gripais ${ }^{2}$.

$\mathrm{O}$ eritema multiforme pode atingir indivíduos de qualquer idade, contudo, sua predileção acontece na terceira e quarta décadas de vida, embora também possa acometer crianças e adolescentes ${ }^{3}$.

Conforme o grau de severidade e comportamento da pele e mucosa, o EM é subdividido em oral, secundário e primário. Quando o EM estiver relacionado a desordens mais severas, alguns autores o classificam como síndrome de Stevens e Johnson (SSJ) e necrólise epidérmica tóxica (NET) ${ }^{4}$.

Alguns autores acreditam que EM, SSJ e NET sejam estágios evolutivos da mesma doença. Porém, atualmente, têm aumentado as evidências de que as três sejam entidades distintas, uma vez que apresentam epidemiologia, etiologia, histopatologia e manifestações clínicas diferentes ${ }^{5,6}$.

O EM apresenta-se clinicamente distribuído, de modo simétrico, em mãos, braços, pernas, pés, face e mucosa, com o formato de anéis concêntricos. Tais lesões possuem aspecto de placa de cor eritemo-purpúrica, na maioria das vezes representando lesões bolhosas. As lesões podem apresentar prurido e evoluir para uma discreta descamação e um aumento de pigmentação e, ainda, podem causar dor, ardência, sensação de queimação, acometendo bochecha, lábio, palato, gengiva e língua ${ }^{7}$. No vermelhão do lábio, aparece como crostas eritematosas com placas esbranquiçadas ${ }^{8}$.

O EM oral é reconhecido por causar ulcerações crônicas na mucosa, sendo uma doença rara com características únicas sem causar lesões típicas em pele $^{9}$. A etiologia é desconhecida, todavia, são vários os possíveis agentes causadores (bacterianos, viróticos, infecções por fungos, drogas, radioterapia e tensão emocional) ${ }^{10}$. Alguns pacientes examinados apresentaram lesões bucais queratinizadas e não queratinizadas na mucosa e no vermelhão do lábio ${ }^{11}$.

O EM secundário ou menor apresenta-se de forma benigna e as manifestações são principalmente em pele e sem comprometimento de mucosa. Podem haver lesões bolhosas que envolvam menos que $10 \%$ da superfície do corpo e com maior preferência em membros extensores. A duração das lesões é de uma a três semanas ${ }^{12,13}$. Já o eritema multiforme primário ou maior representa um tipo mais severo da doença, com grave comprometimento mucocutâneo e alterações no estado de saúde geral do paciente. Apresenta características importantes mais evidentes que o eritema multiforme menor ${ }^{9}$ e tem curso de um a quatorze dias.

$\mathrm{O}$ eritema multiforme inicia-se como uma reação primária a antígenos, que podem ser drogas ou resultantes de variados tipos de infecções, dentre elas o vírus do herpes ${ }^{14}$.

Em um trabalho realizado em 2003, os autores relatam as principais drogas e as infecções que estão relacionadas ao aparecimento do EM; dentre as drogas, estão salicilatos, barbitúricos, diclofenaco e felilbutazona. Dentre as infecções relatadas, estão o herpes, as hepatites, a aids e a influenza $\mathrm{A}^{9}$.

O diagnóstico é clínico e pela avaliação da história médica e medicamentosa do paciente, geralmente, exames laboratoriais não revelam nenhuma anormalidade significativa. A imunofluorescência é o exame complementar mais utilizado e específico, já que apenas o resultado do histopatológico não define o diagnóstico e nem exclui os diagnósticos diferencias $^{15}$.

Dependendo da severidade das lesões, o tratamento pode ser sintomático, com analgésicos tópicos ou sistêmicos e enxaguantes bucais ${ }^{16}$. O paciente deve ser orientado a se alimentar com dieta macia, evitar alimentos ácidos e picantes e ingerir bastante água ${ }^{17,18}$.

Para o tratamento das lesões intraorais, podem ser usados corticoides na forma de bochecho ou sistêmico. Porém, antes disso, o cirurgião deve avaliar corretamente o caso e certificar-se de que não se trata de uma lesão viral. É recomendado o uso de prednisona $30 \mathrm{mg}$ a $50 \mathrm{mg}$ ao dia, por vários dias e diminuindo as doses progressivamente ${ }^{19}$.

Outros fármacos também têm demonstrado efeito favorável no tratamento de EM, como azatioprina de $100 \mathrm{mg}$ a $150 \mathrm{mg}$ ao dia, indicado para casos severos quando todos os outros medicamentos apresentaram falhas; talidomida, dapsona e mofetil também mostraram-se eficientes ${ }^{18,20}$. O mofetil foi o que apresentou melhores resultados em comparação a outros imunossupressores.

\section{Relato de caso}

O presente trabalho foi aprovado pelo Comitê de Ética em Pesquisa da Universidade de Passo Fundo, pelo parecer $\mathrm{n}^{\mathbf{0}}$ 611/2011 e Certificado de Apresentação para Apreciação Ética no 0280.0.398.000-11. A paciente em questão autorizou a publicação do caso por meio da assinatura de um termo de consentimento livre e esclarecido.

Trata-se de paciente feminina, com 38 anos de idade, que procurou atendimento odontológico 
apresentando dificuldade de fonação, deglutição e utilização de aparelho protético devido à presença de lesões bucais dolorosas. Inicialmente, a paciente relatou que já esteve consultando alguns médicos devido às lesões e que sua hipótese era de lúpus eritematoso. Tal diagnóstico não foi confirmado, uma vez realizados exames complementares (hemograma, anti-HIV, anti-HCV, biópsia intestinal, endoscopia digestiva, pesquisa do fator reumatoide e exame histopatológico de lábio). Também relatou que as lesões bucais começaram a surgir um mês após o uso de uma medicação antidepressiva, o cloridrato de bupropiona (Glaxo Smith Kline, Rio de Janeiro, RJ, Brasil). No exame físico da paciente, foi observada face simétrica, lábios ressecados e mucosa ocular irritada (Figura 1).

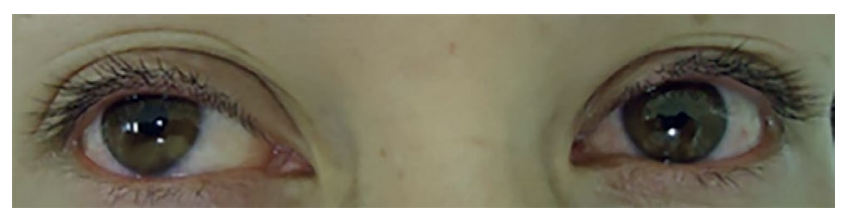

Figura 1 - Aspecto da mucosa ocular hiperêmica da paciente

Fonte: elaboração dos autores.

Também foi notada a presença de lesões ulceradas com máculas eritematosas na mucosa jugal, sobre o rebordo alveolar e palato, as quais apresentavam sangramento ao toque. A paciente informou que previamente às lesões ulceradas surgiam bolhas na boca, que se rompiam rapidamente, deixando áreas ulceradas dolorosas, incluindo no diagnóstico diferencial as lesões vesiculobolhosas ulceradas, como pênfigo, penfigoide benigno das mucosas e eritema multiforme (Figura 2).
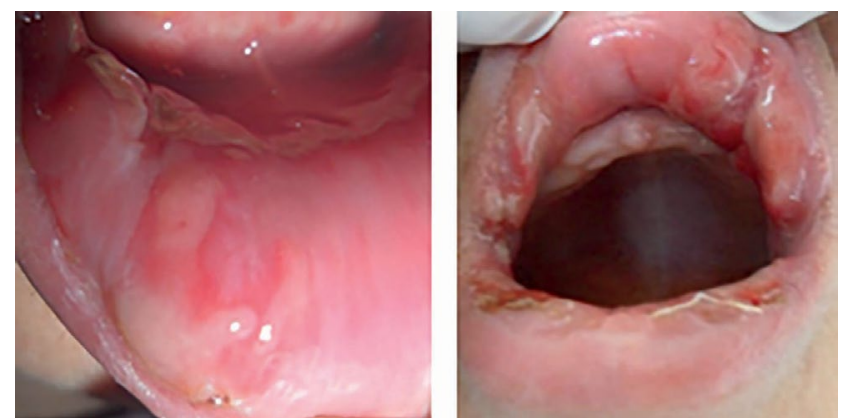

Figura 2 - Esquerda - lesões ulceradas em mucosa labial inferior, estendendo-se ao fundo de vestíbulo. Direita - lesões crostosas em semimucosa labial inferior e ulceradas em mucosa labial superior

Fonte: elaboração dos autores.

Diante do aspecto clínico, foram removidas duas amostras de tecido do lábio inferior por meio de biópsia incisional, as quais foram encaminhadas para exame histopatológico e de imunofluorescência. Os resultados associados ao aspecto e à história clínica confirmaram a hipótese diagnóstica de EM (Figura 3).

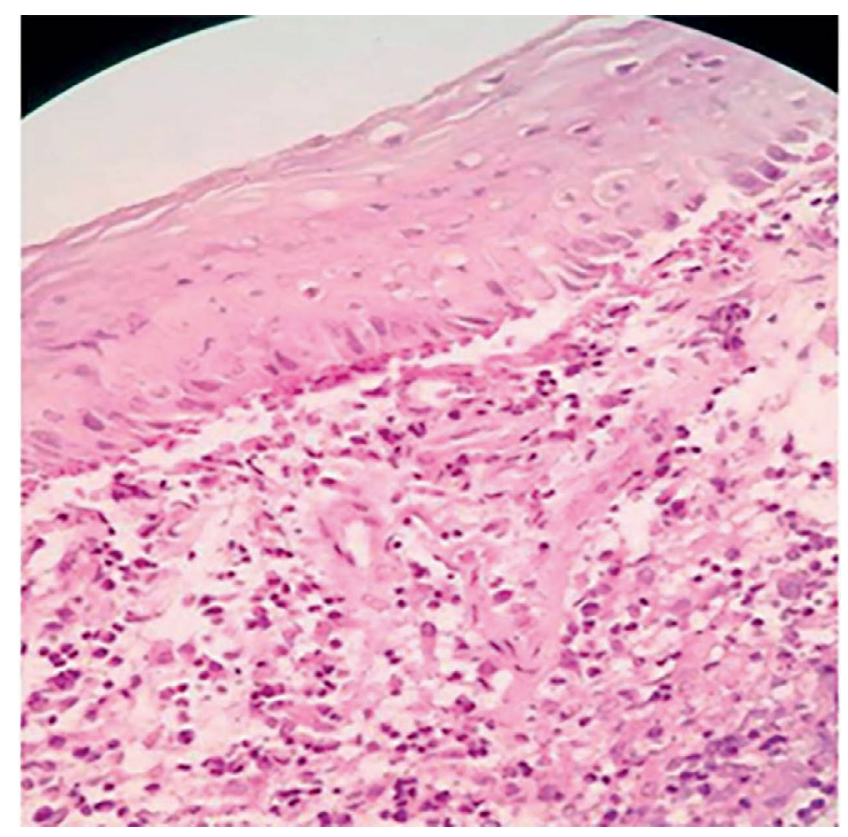

Figura 3 - Aspecto histopatológico do eritema multiforme mostrando infiltrado inflamatório e proliferação vascular no tecido conjuntivo, bem como algumas áreas de edema inter e intracelular (H.E. 400X)

Fonte: elaboração dos autores.

Tendo em vista o diagnóstico definitivo de EM, a conduta foi prescrição de nistatina solução oral 100.000 U.I. (Laboratório Cristalia, Nova Itapira, SP, Brasil), Prednisona (Meticorten $\left.{ }^{\circledR}\right) 20 \mathrm{mg}$, duas vezes ao dia (Laboratório Mantecorp, São Paulo, SP, Brasil) por cinco dias e uma vez ao dia pelos cinco dias subsequentes, além de bochecho com Dexametasona elixir duas vezes ao dia (Decadron ${ }^{\circledR}$, Aché Laboratórios Farmacêuticos S.A., Guarulhos, SP, Brasil). Após dez dias, a paciente foi reavaliada, tendo-se observado uma evidente melhora do quadro clínico (Figura 4), visto que as lesões já se encontravam em fase de cicatrização, possibilitando a utilização de suas próteses. Nesse momento, a paciente foi orientada a diminuir gradativamente a dose da medicação prescrita bem como a consultar seu médico a fim de verificar a possibilidade de substituir o cloridrato de bupropiona por outro antidepressivo, uma vez que esse poderia ter influência na origem das lesões.
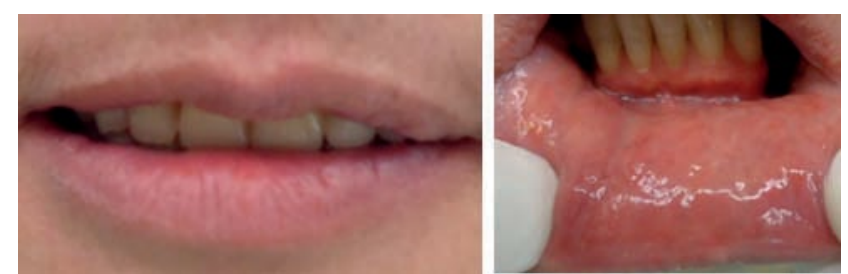

Figura 4 - Aspecto da semimucosa (esquerda) e mucosa (direita) labiais mostrando a remissão das lesões após tratamento com corticosteroide

Fonte: elaboração dos autores.

Em nova consulta, realizada após duas semanas, a paciente informou que deixou de utilizar o cloridrato de bupropiona e não notou mais indícios 
de lesões bucais ou oculares, o que confirma, com acompanhamento clínico de dois anos, que o cloridrato de bupropiona foi o causador do EM.

\section{Discussão}

As lesões vesiculobolhosas constituem um grupo variado de doenças que ocorrem na cavidade bucal, de grande importância clínica pela forma variada com que se apresentam, pela frequência observada e também pela dificuldade de diagnóstico de algumas dessas desordens. Por serem alterações autoimunes ou de hipersensibilidade, a aparência clínica é muito semelhante e a etiologia pode ser difícil de ser encontrada, necessitando, assim, de um estudo minucioso dessas lesões.

No caso ora apresentado, a paciente apresentava lesões simétricas, como máculas eritematosas e úlceras intrabucais variando de $2 \mathrm{~mm}$ a $3 \mathrm{~mm}$. Também foram relatadas bolhas e lesões crostosas no vermelhão dos lábios. A paciente queixou-se ainda de dor nas articulações e cansaço.

Diversos autores afirmam que o EM pode atingir indivíduos de qualquer idade, mas sua predileção é entre a terceira e a quarta décadas de vida, embora também possa acometer crianças e adolescentes $^{3,17,21,22}$. No caso observado, a paciente pertencia ao sexo feminino era, branca, com 40 anos de idade.

Conforme o grau de severidade e o comportamento da pele e mucosa, o EM é subdividido em secundário, primário e oral. Quando o EM estiver relacionado a desordens mais severas, alguns autores o classificam como SSJ e $\mathrm{NET}^{4}$.

Quando o EM é diagnosticado em adultos, em $60 \%$ dos casos está associado ao vírus do herpes ${ }^{7}$. O EM causado por drogas é relacionado a SSJ e ou a NET. No presente caso, não se verificou relação com o vírus do herpes, pois as manifestações iniciaram após a utilização de um fármaco específico: cloridrato de bupropiona. A literatura demonstrou haver uma relação concreta entre determinados tipos de fármacos e o aparecimento do EM, como mostra um estudo que comparou a relação das manifestações cutâneas de doenças autoimunes com a mucosa oral $^{22}$. Não há nenhuma evidência objetiva de que a quantidade ou a intensidade da droga possam ou não causar uma reação adversa. O número de drogas causadoras do EM são diversas, podendo-se citar: antipiréticos, barbitúricos, fenobarbital e fenilbutazona. Foram encontrados, ainda, na literatura dois relatos de casos de EM e SSJ causados pela bupropiona $^{17}$. Outro achado que também induz ao diagnóstico é a leitura da bula do medicamento, na qual consta EM nas "reações adversas".

Na mucosa bucal, o EM se apresenta como máculas, pápulas ou placas eritematosas, com formação de vesícula ou bolha. Após o rompimento dessas bolhas, observa-se no epitélio presença de erosão e ulceração cobertas por pseudomembrana. As lesões podem causar dor, ardência e/ou sensação de queimação. Acometem bochecha, lábio, palato, gengiva e língua. No vermelhão do lábio, aparecem como crostas eritematosas com placas esbranquiçadas ${ }^{8}$. No presente caso, as características anteriormente descritas foram notadas, impossibilitando a paciente de se alimentar corretamente. Não foram observadas lesões de pele, com exceção do relato por parte da paciente de pequenas crostas no couro cabeludo.

Os exames complementares indicados para o diagnóstico do EM são: hemograma, fator reumatoide, imunofluorescência direta, anti-HIV, história de lesões por herpes vírus e história de uso de medicamentos, como os descritos na literatura. No caso estudado, foram realizados esses exames para confirmação do diagnóstico e exclusão de outras doenças.

$\mathrm{Na}$ literatura, o EM é descrito histologicamente como: edema intra e intercelular infiltrado, inflamatório misto de linfócitos $\mathrm{T}$, devido à presença de hipersensibilidade imunológica. A imunofluorescência direta e indireta é negativa e serve apenas para descartar outros processos inflamatórios ${ }^{17}$.

O lúpus eritematoso, que é uma doença autoimune, hipótese de diagnóstico inicial dos médicos, foi descartado pelos resultados negativos dos exames hematológicos e da biópsia realizada. Descartou-se tal enfermidade, também, porque tem como características clínicas mancha malar, artrite, úlceras e problemas hematológicos, problemas que não estavam presentes na paciente em questão.

O exame histopatológico da biópsia realizada na paciente revelou um padrão que pode ser característico de eritema multiforme. $\mathrm{O}$ anatomopatológico na descrição microscópica revelou fragmentos de mucosa exibindo epitélio de revestimento com acantose e degeneração hidrópica. No tecido conjuntivo, neocapilares e vasos dilatados e infiltração de linfócitos e eosinófilos. O histopatológico por imunofluorescência indireta apresentou resultado negativo, bem como a imunofluorescência direta.

Todas as características juntas, incluindo as clínicas e histológicas, a utilização de fármacos, a recorrência dos sintomas e a exclusão de outros diagnósticos diferenciais levaram a concluir o diagnóstico de EM.

Para o tratamento das lesões intraorais, podem ser usados corticoides de forma sistêmica ou de bochecho, porém, antes, o cirurgião deve avaliar corretamente o caso e certificar-se de que não se trata de uma lesão viral. A literatura preconiza o uso de $30 \mathrm{mg}$ de prednisona diariamente, por dez dias, e diminuir as doses gradativamente até chegar a $10 \mathrm{mg}$ em dias alternados ${ }^{23}$. Existem, hoje, controvérsias sobre o uso de corticoides sistêmicos para o tratamento de EM. Estudos demonstram que tal fármaco pode aumentar a frequência da doença e também a sua cronicidade ${ }^{24}$.

No caso apresentado, o tratamento foi iniciado com $20 \mathrm{mg} /$ dia de Meticortem, por 10 dias, e bochechos intraorais com Decadron 3 vezes ao dia, já que 
foi descartada a relação com o herpes vírus. Devido à frequência das ulcerações, a dose foi aumentada para $40 \mathrm{mg} /$ dia por mais 10 dias, juntamente com o bochecho de Decadron. Após os 10 dias, a dose foi sendo diminuída para $5 \mathrm{mg}$ ao dia até chegar ao final do tratamento e o desaparecimento das lesões.

Para a exclusão de outras doenças como penfigoide benigno das membranas mucosas e do pênfigo vulgar, o diagnóstico foi embasado na literatura, observando o gênero, a idade da paciente e as características predominantes das lesões, bem como a exclusão por exames histopatológicos e imunológicos, nos quais o PV caracteriza-se histologicamente pela formação de uma vesícula ou bolha inteiramente intraepitelial, logo acima da camada basal, produzindo uma fenda suprabasilar bem visível. Apresenta, ainda, relativamente, pouca infiltração de células inflamatórias, tanto no líquido da vesícula como no tecido conjuntivo da base da vesícula ou bolha, sendo essa a característica mais importante para $o$ diagnóstico da doença.

$\mathrm{Na}$ imunofluorescência direta no pênfigo vulgar, revela-se o depósito de anticorpos IgG-1 e IgG-4 contra os antígenos epiteliais em meio dos espaços intercelulares ${ }^{23}$. Já o PBM apresenta como característica histopatológica um significado bastante expressivo no diagnóstico, pois se pode observar a separação da membrana basal epitelial do tecido conjuntivo subjacente, ocasionando vacuolização e bolhas subepiteliais, permanecendo a superfície epitelial intacta ${ }^{24}$. No exame de imunofluorescência direta, demonstra-se padrão linear de IgG na membrana basal. Essas hipóteses foram descartadas pelos resultados negativos obtidos nos exames complementares do presente caso.

\section{Considerações finais}

As doenças vesiculobolhosas, em especial o eritema multiforme, são frequentes, e o cirurgião-dentista deve estar preparado para diagnosticar e iniciar seu tratamento. São lesões com características clínicas e fatores etiológicos semelhantes que devem ser criteriosamente observadas, sendo que o diagnóstico deve ser feito com base nos achados clínicos, histopatológicos, história clínica minuciosa e exclusão dos diagnósticos diferenciais por meio de exames complementares.

\section{Abstract}

Introduction: Erythema multiforme (EM) is a disease that may affect skin and mucous membranes, and has major clinical importance because of the frequency and variety of entities that it may represent. It is difficult to diagnose, likely because of patient hypersensitivity. Objective: This study aims to report an unusual case of EM related to antidepressant use. Case report: Female patient, 38 years old, reporting the appearance of ulcers preceded by blisters in the oral cavity about a month after starting antidepressant treatment using bupropion hydrochloride. The history and clinical aspects of skin and oral lesions were assessed, as well as histopathological and immunofluorescence findings, thus excluding differential diagnoses and obtaining the diagnosis of EM. The patient was treated with topical and systemic oral corticosteroids, removing the antidepressant drug. Final considerations: Because this disease may affect the oral cavity, resulting in extensive ulcerative lesions that are very uncomfortable to the patient, the dentist should know its clinical, diagnosis, treatment, and prognosis aspects.

Keywords: Antidepressive agents. Erythema multiforme. Diagnosis. Therapy.

\section{Referências}

1. Auquier-Dunant A, Mockenhaupt M, Naldi L, Correia O, Schröder W, Roujeau J-C. Correlations between clinical patterns and causes of Erythema Multiforme Majus, Stevens-Johnson Syndrome, and Toxic Epidermal Necrolysis, Arch. Dermatol 2002; 138(8):1019-24.

2. Tommasi AF. Diagnóstico em patologia bucal. 3. ed. São Paulo: Poncast; 2002.

3. Lindhe J. Tratado de periodontia clínica e implantologia oral. 3. ed. Rio de Janeiro: Guanabara Koogan; 1998.

4. Khalid A, Al-Johani BDS, Fedele S, Porter SR. Erytema multiforme and related disorders. Oral Surg Oral Med Oral Pathol Oral Rad e Endod 2007; 103(5):642-54.

5. Luna DMN, Carvalho AAT. Eritema multiforme - uma revisão. Int J Dent 2008; 7(1):63-8.

6. Williams PM, Conklin RJ. Erythema multiforme: a review and contrast from Stevens-Johnson syndrome/toxic epidermal necrolysis. Dent Clin North Am 2005; 49(1):67-76.

7. Mangnaro A. Erythema multiforme. Gen Dent 1996; 44(2)164-6.

8. Ayangco L, Sheridan PJ, Rogers III RS. Oral manifestations of erythema multiforme. Dermatol Clin 2003; 21(1):195-205.

9. Kennett S. Erythema multiforme affecting the oral cavity. Oral Surg Oral med Oral pathol 1968; 25(3):366-73.

10. David A, Wetter MD, Mark DP, Davis MD. Recurrent erythema multiforme: Clinical characteristics, etiologic association, and treatment in a series of 48 patients at Mayo Clinic, 2000 to 2007. J Am Acad Dermatol 2010; 62(1):45-53.

11. Bastuji-Garin S, Rzany B, Stern S. Clinical classification of cases of toxic epidermal necrolysis, Stevens-Johnson syndrome, and erythema multiforme. Arch Dermatol 1993; 129(1):92-6.

12. Roujeau JC. Stevens-Johnson syndrome and toxic epidermal necrolysis are severity variants of the same disease which differs from erythema multiforme. J Dermatol 1997; 24:726-9.

13. Steven Am, Johnson FC. A new eruptive fever associated with stomatitis and ophthalmia. Am J Dis Child 1922; 24:526-33.

14. Fritsch PO, Maldonado RR. Stevens-Johnson syndrome- toxic epidermal necrolysis. Dermatol Gen Med 1993; 2(4):644-54.

15. Fernández García JR, Alcaraz Vera M, Ruiz Jiménez MA. Eritema multiforme. Rev Esp Pediatria 2000; 56:202-5.

16. Gavaldá-Esteve C, Murillo-Cortés J, Poveda-Roda R. Eritema multiforme. Revisión y puesta al dia. RCOE 2004; 9(4):415-23. 
17. Ayangco L, Sheridan PJ, Rogers III RS. Erythema multiforme secondary to herpes simplex infection: a case report. $J$ Periodontol 2001; 72(7):953-7.

18. Bagán-Sebastián JV. Enfermedades ampollares de la cavidad oral (III): Eritema multiforme, dermatosis IGA lineal, dermatitis herpetiforme y epidermólisis ampollar. En: Bagán-Sebastián JV, Ceballos-Salobreña A, Bermejo-Fenoll A, Aguirre-Urizar JM, Peñarrocha-Diago M, editores. Medicina Oral. Barcelona: Masson; 1995. p. 234-40.

19. Ruiz L, Morales Larios E, Díaz Ricomá N. Úlceras orales y rash eritematopapuloso em varón de 17 años. Rev Clín Esp 2003; 203(10):491-2.

20. Schofield JK, Tatnall FM, Leigh IM. Recurrent erythema multiforme: clinical features and treatment in a large series of patients. Br J Dermatol 1993; 128(5):542-5.

21. Gonçalves LM, Bezerra JRS, Cruz MCFN. Clinical evaluation of oral lesions associated with dermatologic diseases. An Bras Dermatol 2010; 85(2):150-6.

22. Farthing PM, Maragou P, Coates M, Tatnall F. Characteristics of the oral lesions in patients with cutaneous recurrent erythema multiforme. J Oral Pathol Med 1995; 24(1):9-13.

23. Ferreira FA, Filippini PA, Beltrame M, Guirra FR, Barreto MP. Manifestações bucais do Pênfigos Vulgar e Bolhoso. Odontologia Clin-cientific 2009; 8(4):293-8.

24. Scully C, Bagan J. Oral mucosal diseases Erythema multiforme. Br J Oral Maxillofacial Surg 2008; 46(2):90-5.

Endereço para correspondência:
João Paulo De Carli
Universidade de Passo Fundo
Faculdade de Odontologia
BR 285, São José
99052-900 Passo Fundo, RS
E-mail: joaodecarli@upf.br

Recebido: 14/04/15. Aceito: 03/06/16. 